\title{
Fear of COVID-19 and Related Factors in Emergency Department Patients
}

\author{
Yeliz Sürme $^{1}$ (D) Nurten Özmen ${ }^{2}$ (D) $\cdot$ Bade Ertürk Arik $^{3}$ (D)
}

Accepted: 15 June 2021/ Published online: 29 June 2021

(C) The Author(s), under exclusive licence to Springer Science+Business Media, LLC, part of Springer Nature 2021

\begin{abstract}
This study was aimed to determine the fear of COVID-19 and related factors in patients. This study was conducted with 639 patients who were admitted to the emergency department. Data were collected using the sociodemographic characteristics form, Fear of COVID-19 scale (FCV-19S). The data were evaluated with Student's t-test to compare two groups and one-way ANOVA and post hoc Tukey's honestly significant difference (HSD) more than two groups. Multiple linear regression analysis was used to determine the relationship between dependent and independent variables. The mean age of patients was $46.12 \pm 17.02,53.4 \%$ were male, $70.7 \%$ were married, $42.4 \%$ had a chronic disease, $18.3 \%$ stated that they had symptoms of COVID-19, and $38.0 \%$ stated that they experienced economic difficulties due to COVID-19. The COVID-19 fear scores were significantly higher in 57 ages and over, female, had lung disease, had COVID-19 symptoms, and had children. Having a lung disease, female gender, and fear of COVID-19 were statistically significantly correlated with FCV-19S scores. As a result, it was determined that patients admitted to the emergency department had fear of COVID-19. Further research is recommended to support our study findings. As an emergency nurse, strategies must be developed to cope with these fears.
\end{abstract}

Keywords COVID-19 · Emergency $\cdot$ Fear

Yeliz Sürme

yelizcucuk@hotmail.com

Nurten Özmen

nurtenurten47@gmail.com

Bade Ertürk Arik

badeerturk@gmail.com

1 Department of Nursing, Faculty of Health Sciences, Erciyes University, Kayseri, Turkey

2 Emergency Room Nurse, Tomarza Yaşar Karayel State Hospital, Kayseri, Turkey

3 Belsin Family Health Center, Kayseri, Turkey 
Coronavirus 19 (COVID-19) or SARS-CoV-2 infectious disease emerged in China in early December 2019 (Wu and McGoogan, 2020). In March, the World Health Organization (WHO) evaluated the situation and declared a pandemic (WHO, 2020).

Pandemic diseases such as COVID-19 with a very high transmission rate and without an effective treatment caused the spread of fear among people (Ornell et al. 2020). Studies have indicated that there is a fear of COVID-19 in various patient groups, healthcare workers, and the general population (Catania et al. 2020; Labrague and de Los Santos, 2020; Wang et al. 2020).

Like the whole society, patients also have fear of COVID-19 due to the outbreak. It is predicted that individuals admitted to the emergency department (ED) will also have fear of COVID-19 (Açıksarı and Kınık, 2020).

Emergency departments are kind of entrance gates and visible units where hospitals accept patients without waiting in line or waiting for an appointment (Saghafian et al. 2015). In a study, it was stated that after the pandemic announcement, in an ED in Turkey, there were fewer patients' admissions in April as compared to other years. It was determined that the ED admission in April 2020 decreased from 49.9 to 33.2\% compared to 2019 and decreased by $49.7 \%$ compared to the previous month. Researchers stated that the reason for this could be the fear of COVID-19 (Açıksarı and Kınık, 2020). Similar results have been reported in Portugal and Italy (Correia et al. 2020; Comelli et al. 2020). The fear of COVID-19 causes patients with health problems to avoid going to the hospital. In addition, fear reduces the quality of life in patients and negatively affects compliance with medical treatment. It also affects the frequency of pain, nausea and vomiting, and even the side effects of medications (Sigorski et al. 2020). Therefore, firstly, this fear should be defined, in order to control the fear in patients. On the other hand, there are a number of studies on the psychological effects of COVID-19 in different patient groups (Catania et al. 2020; Sigorski et al. 2020; Vanni et al. 2020; Casanova et al. 2020). However, we did not come across any study investigating the COVID-19 fear of patients admitted to the ED.

To the best of our knowledge, there was no similar study previously undertaken on the fear of COVID-19 in ED patients. Therefore, this study aimed to determine the fear of COVID-19, in ED patients.

\section{Methods}

\section{Study Design and Sample}

This is a descriptive and cross-sectional study. The data were collected between October 7, 2020-December 31, 2020, in a state hospital in the Central Anatolia region of Turkey.

The study population consisted of patients who met the inclusion criteria: (1) the age of 18 and older, (2) wanted to participate in the study, (3) did not have a mental illness, (4) were conscious and literate. Twenty patients did not meet the inclusion criteria, 5 patients did not want to participate in the study and 3 patients did not complete the questionnaire. Finally, a total of these 28 patients were excluded from the study. The study was completed with 639 patients.

The adequacy of the sample was decided based on post hoc power analysis. When the type I error was taken as $5 \%$, the sample size as 639 , effect size 0.153 , the posterior power of the study was calculated as $98 \%$. 


\section{Data Collection}

The data were collected by the researcher using the face-to-face interview. Patients answered the questionnaire, during the treatment and after the doctor examined them. The data collection period lasted for $5 \mathrm{~min}$.

\section{Data Collection Tools}

Data were collected using the sociodemographic characteristics form, and the fear of COVID19 scale.

The Sociodemographic Characteristics Form This form was created by the researchers by scanning the literature (Bakioğlu et al. 2020; Perz et al. 2020; Ahorsu et al. 2020). This form consisted of 13 open-ended and multiple-choice questions obtaining demographic information such as age, gender, marital status, occupation, presence of chronic disease, the reason for admission to the ED, whether the patient has symptoms of COVID-19, and the presence of a relative with COVID-19.

Fear of COVID-19 Scale This scale was developed by Ahorsu et al. in Iran that consists of seven items and has a one-dimensional structure. The original language of the scale is Persian. The scale has a 5-point Likert-type rating system (1: Strongly disagree and 5: Strongly agree). The Cronbach's alpha value of the scale was 0.82 (Ahorsu et al. 2020). The validity and reliability study of the scale in our country was made and adapted to Turkish by Bakioğlu et al. The Cronbach's alpha value of the scale was 0.88 . The scores that can be obtained from the scale are between 7 and 35. The scale does not have a cut-off point. As the score obtained from the scale increases, the fear of COVID-19 increases (Bakioğlu et al. 2020). In our study, Cronbach's alpha value of the scale was found to be 0.80 .

\section{Ethical Considerations}

The approval from Erciyes University's non-interventional clinical research ethics committee $(2020 / 515)$ was obtained before the study. Informed consent was obtained from the patients. In addition, study permission on COVID-19 was obtained from the Ministry of Health.

\section{Statistical Analysis}

The data were analyzed by SPSS 24.0 (IBM Corp., Armonk, USA). Descriptive statistics were given as number, percentage, and mean \pm standard deviation. Shapiro-Wilk test and Q-Q graphs were used to determine whether the numerical data were suitable for normal distribution. The data with normal distribution were analyzed with Student's t-test to compare two groups and one-way ANOVA, post hoc Tukey's honestly significant difference (HSD) more than two groups. Multiple linear regression analysis was used to determine the relationship between dependent and independent variables. In all results, $\mathrm{p}<0.05$ was considered statistically significant. 
The independent variables of the study were the introductory information such as age, gender, presence of chronic disease, having a lung disease, having a child, and presence of COVID-19 symptoms. The dependent variable of the study was FCV-19S scores.

\section{Results}

The mean age of patients was $46.12 \pm 17.02$, and $53.4 \%$ of them were male, $70.7 \%$ were married, $42.4 \%$ had a chronic disease, and $53.6 \%$ had at least one child. $18.3 \%$ of the patients stated that they had symptoms of COVID-19, and $38.0 \%$ stated that they experienced economic difficulties due to COVID-19. Of the patients, $23.0 \%$ admitted to the ED because of fever, cough, and weakness, which are considered COVID-19 symptoms. The mean score of FCV-19S was $19.25 \pm 6.01$ (Table 1).

FCV-19S scores were statistically significantly higher in those 57 ages and over, female, had a chronic disease, had lung disease (asthma, bronchitis, COPD, etc.), had children, and those who had COVID-19 symptoms $(\mathrm{p}<0.05)$ (Table 2). There was not found a significant relationship between FCV-19S scores, marital status, and occupation ( $\mathrm{p}>0.05)$.

Multiple linear regression analysis was performed for gender, having a lung disease, fear of COVID-19, and FCV-19S. The model was statistically significant $(\mathrm{F}=9.733, \mathrm{p}<0.001 ; \mathrm{R} 2=$ 0.088). Having a lung disease, female gender, and fear of COVID-19 were statistically significant predictors of FCV-19S scores. Having a lung disease is responsible for $18.5 \%$, the female gender is responsible for $20.0 \%$, and fear of COVID-19 is responsible for $15.4 \%$ of the change in FCV-19S scores. The most influential factor related to FCV-19S was female gender $(\beta=0.200, \mathrm{p}<0.05)$ (Table 3$)$.

\section{Discussion}

Compared with the general population, patients are more likely to experience negative emotions because of COVID-19. Fear and anxiety play an important role in the course of patients' illness, even in the normal process (Vanni et al. 2020). In our study, the mean score of FCV-19S was $19.25 \pm 6.01$ and $74.8 \%$ of the patients were fearful of the COVID-19. Our study results are in line with the literature. In a case report of a patient who had kidney stones and was admitted to the ED with abdominal pain and anuria complaints, it was stated that he did not go to the hospital due to fear of COVID-19 and as a result, signs of kidney failure were developed (Romantini et al. 2020). In a qualitative study, it was reported that most emergency room patients have a fear of contracting the virus. In the same study, one of the patients stated that being infected with COVID-19 is more important than his current health status, while another patient stated that he would die if he contracted COVID-19 (WongLaura et al. 2020). In another study conducted in the (United States) US, it was stated that after the pandemic announcement by the World Health Organization, the number of patients admitted to the ED in New York City and Baton Rouge decreased by 66\%, and this may be due to the fear of COVID-19 (Boserup et al. 2020). In addition, a decrease in the number of patients admitted to the ED was reported in Italy and Spain after the pandemic announcement (Garrafa et al. 2020; Castro and Perlis, 2020). Similar results were found in different patient groups. In a study conducted with patients who had lung cancer, it was stated that $19.9 \%$ of the patients were extremely fearful of the COVID-19 outbreak (Catania et al. 2020). In another study, it was 
Table 1 Descriptive characteristics of the patients (N: 639)

\begin{tabular}{|c|c|c|}
\hline Descriptive characteristics & $\mathrm{n}$ & $\%$ \\
\hline \multicolumn{3}{|l|}{ Age (years) } \\
\hline $18-30$ & 151 & 23.6 \\
\hline $31-43$ & 147 & 23.0 \\
\hline $44-56$ & 137 & 21.4 \\
\hline$\geq 57$ & 204 & 31.9 \\
\hline$\overline{\text { Mean age }} \pm \mathrm{SD}(\min -\max )$ & \multicolumn{2}{|c|}{$46.12 \pm 17.02(18-88)$} \\
\hline \multicolumn{3}{|l|}{ Gender } \\
\hline Female & 298 & 46.6 \\
\hline Male & 341 & 53.4 \\
\hline \multicolumn{3}{|l|}{ Marital status } \\
\hline Married & 452 & 70.7 \\
\hline Single & 187 & 29.3 \\
\hline \multicolumn{3}{|l|}{ Having a child } \\
\hline Yes & 489 & 76.5 \\
\hline No & 150 & 23.5 \\
\hline \multicolumn{3}{|l|}{ Occupation } \\
\hline Worker & 116 & 18.2 \\
\hline Officer & 46 & 7.2 \\
\hline Retired & 91 & 14.2 \\
\hline Self-employment & 139 & 21.8 \\
\hline Unemployed & 247 & 38.7 \\
\hline \multicolumn{3}{|l|}{ Presence of chronic disease } \\
\hline Yes & 271 & 42.4 \\
\hline No & 368 & 57.6 \\
\hline \multicolumn{3}{|l|}{ Chronic disease (n: 271) } \\
\hline Diabetes mellitus & 54 & 19.9 \\
\hline Hypertension and heart disease & 125 & 46.1 \\
\hline Lung diseases & 92 & 14.4 \\
\hline \multicolumn{3}{|l|}{ Presence of COVID-19 symptoms } \\
\hline Yes & 117 & 18.3 \\
\hline No & 522 & 81.7 \\
\hline \multicolumn{3}{|c|}{ Presence of a relative with COVID-19 } \\
\hline Yes & 113 & 17.7 \\
\hline No & 526 & 82.3 \\
\hline \multicolumn{3}{|c|}{ Experiencing economic difficulties due to COVID-19 } \\
\hline Yes & 243 & 38.0 \\
\hline No & 396 & 62.0 \\
\hline \multicolumn{3}{|l|}{ Reason for admitted to the ED } \\
\hline Fever, cough, weakness & 147 & 23.0 \\
\hline Abdominal pain & 100 & 15.6 \\
\hline Nausea-vomiting & 68 & 10.6 \\
\hline Headache, dizziness & 132 & 20.7 \\
\hline Chest pain & 75 & 11.7 \\
\hline Trauma & 117 & 18.3 \\
\hline \multicolumn{3}{|l|}{ Fear of COVID-19 } \\
\hline Yes & 478 & 74.8 \\
\hline No & 161 & 25.2 \\
\hline FCV-19S $($ Mean \pm SD) & & \\
\hline
\end{tabular}

stated that the number of newly diagnosed cancer patients decreased significantly during the pandemic period and mortality could increase due to delayed early diagnosis (Kaufman et al. 2020). In light of these findings, it is important to raise patient awareness regarding acute and fatal illnesses. As a nurse, it is thought that defining and managing patients' fears can contribute to the patients' coping with these emotions and their compliance with treatment. 
Table 2 Fear of COVID-19 of the patients according to the descriptive characteristics (n: 639)

\begin{tabular}{|c|c|c|}
\hline Descriptive characteristics & $\begin{array}{l}\text { FCV-19S } \\
\text { Mean } \pm \text { SD }\end{array}$ & Statistical analysis \\
\hline \multicolumn{3}{|l|}{ Age } \\
\hline $18-30$ & $17.80 \pm 5.82^{\dagger}$ & \multirow[t]{4}{*}{$\mathbf{p}<0.01^{\dagger}$} \\
\hline $31-43$ & $18.81 \pm 5.89$ & \\
\hline $44-56$ & $19.97 \pm 5.40$ & \\
\hline$\geq 57$ & $20.15 \pm 6.43^{\dagger}$ & \\
\hline \multicolumn{3}{|l|}{ Gender } \\
\hline Female & $20.69 \pm 5.91$ & \multirow[t]{2}{*}{$\mathbf{p}<0.001$} \\
\hline Male & $17.99 \pm 5.82$ & \\
\hline \multicolumn{3}{|l|}{ Having a chronic disease } \\
\hline Yes & $20.15 \pm 6.23$ & \multirow[t]{2}{*}{$\mathbf{p}=<0.01^{\ddagger}$} \\
\hline No & $18.59 \pm 5.77$ & \\
\hline \multicolumn{3}{|l|}{ Having a child } \\
\hline Yes & $19.78 \pm 5.88$ & \multirow[t]{2}{*}{$\mathbf{p}<0.001$} \\
\hline No & $17.52 \pm 6.15$ & \\
\hline \multicolumn{3}{|l|}{ Chronic diseases } \\
\hline Diabetes mellitus & $20.48 \pm 5.01$ & \multirow[t]{3}{*}{$\mathbf{p}<0.001^{\dagger}$} \\
\hline Hypertension and heart disease & $18.05 \pm 4.98^{\dagger}$ & \\
\hline Lung diseases & $21.61 \pm 6.65$ & \\
\hline \multicolumn{3}{|l|}{ Having COVID-19 symptoms } \\
\hline Yes & $20.43 \pm 6.20$ & \multirow[t]{2}{*}{$\mathbf{p}=<0.05$} \\
\hline No & $18.98 \pm 5.94$ & \\
\hline \multicolumn{3}{|l|}{ Fear of COVID-19 } \\
\hline Yes & $20.13 \pm 5.62$ & \multirow[t]{2}{*}{$\mathbf{p}<0.001$} \\
\hline No & $16.63 \pm 6.40$ & \\
\hline \multicolumn{3}{|l|}{ Reason for admitted to the ED } \\
\hline Fever, cough, weakness & $19.65 \pm 6.54$ & \multirow[t]{6}{*}{$\mathrm{p}=0.07^{\dagger}$} \\
\hline Abdominal pain & $20.30 \pm 6.26$ & \\
\hline Nausea-vomiting & $18.36 \pm 4.29$ & \\
\hline Headache, dizziness & $19.00 \pm 5.81$ & \\
\hline Chest pain & $19.96 \pm 5.60$ & \\
\hline Trauma & $18.20 \pm 6.32$ & \\
\hline
\end{tabular}

† One-way ANOVA, post hoc Tukey’s HSD analysis was performed, the group that made the difference

$\ddagger$ Student’s t test was performed

Risk factors for the severe course of COVID-19 infection include old age, chronic obstructive pulmonary disease (COPD), hypertension, diabetes mellitus, and coronary artery disease (Pope, 2020). In addition, in studies conducted, it is stated that among patients diagnosed with COVID-19, those with lung disease and the elderly have higher mortality rates (Cummings et al. 2020; Mahil et al. 2021). In line with this literature, in our study, it was

Table 3 The effect of some independent variable on FCV-19S total score: multiple linear regression analysis

\begin{tabular}{llllllll}
\hline Independent variables & $\mathrm{B}^{\dagger}$ & $\mathrm{SE}^{\dagger}$ & $\beta^{\dagger}$ & $\mathrm{t}$ & $\mathrm{P}$ values & $95 \% \mathrm{CI}^{\dagger}$ & $\mathrm{R}^{2}=0.088$ \\
Having a lung diseases & 2.435 & 0.767 & 0.185 & 3.175 & $<0.01$ & 0.925 to 3.945 & $\mathrm{~F}=9.733$ \\
Gender & 2.486 & 0.726 & 0.200 & 3.423 & $<0.01$ & 1.056 to 3.916 & $\mathrm{p}<0.001$ \\
Fear of COVID-19 & 2.338 & 0.884 & 0.154 & 2.644 & $<0.01$ & 0.597 to 4.079 & \\
\hline
\end{tabular}

$\dagger^{\dagger} \mathrm{B}$, unstandardized regression coefficient; SE, standard error; $\beta$, standardized regression coefficient; CI, confidence interval 
found that the FCV-19S mean score was statistically higher in those aged 57 and over, had chronic diseases, and especially had lung diseases such as asthma and COPD ( $\mathrm{p}<0.001$ ). Also, we found that having a lung disease is responsible for $18.5 \%$ of the change on FCV-19S. The authors postulate the reason for this result is that individuals with chronic diseases aware of more severe and sometimes fatal symptoms of COVID-19 infection.

In the literature, it was stated that depression and anxiety scores (Koksal et al. 2020), and fear associated with COVID-19 (Catania et al. 2020; Fitzpatrick et al. 2020) were higher in females. Our study findings are compatible with the literature. Our results showed that the FCV-19S mean scores of females were higher than males $(p<0.05)$. Also, the female gender is responsible for $20.0 \%$ of the change on FCV-19S. This may be due to the inability of males to express their anxiety and fears as easily as females. It may also be because females are more vulnerable and emotional than males. Studies have shown that the fluctuations in ovarian hormone levels are responsible for altered sensitivity to emotional stimuli during certain phases in the menstrual cycle and this may form the basis of a specific vulnerability to psychological disorders in females (Albert and Newhouse, 2019; Li and Graham, 2017; Rubinow and Schmidt, 2019; Soni et al. 2013).

In the studies, people with children had statistically higher levels of anxiety, depression (Koksal et al. 2020), and fear associated with COVID-19 (Fitzpatrick et al. 2020). It was stated that individuals who have children might be fearful of carrying the virus to their children (Catania et al. 2020; Koksal et al. 2020; Wang et al. 2020). Similarly, we found that FCV-19S mean scores of patients with children were higher than those who had no children $(\mathrm{p}<0.05)$.

\section{Limitations}

This study has several limitations. First of all, this study has a cross-sectional design and selfreported measures. Thus, it was difficult to draw a conclusion about a causal association. Another limitation is that this study is carried out on patients admitted to the ED, so it cannot be generalized to all patients groups. Also, this study was conducted within one province and one state hospital's ED of the country; the exclusion of ED patients from other provinces may affect the generalizability of the findings. Finally, the study was made at a single point of time between October 7 , 2020, and December 31, 2020. The results might be different at the late stages of the outbreak.

\section{Conclusion}

This study showed that FCV-19S scores were higher in females, who had children, patients with chronic diseases and lung disease, and those aged 57 and over. Further research is recommended to support our study findings. The first step in preventing fear is to determine it correctly and clearly. So, it is recommended to define patients' fears and develop strategies to cope with these fears. To reduce the COVID-19 fears of patients, specialist consultation may be requested and directed to relaxation therapies. Thus, the treatment process of the patients is not interrupted and complications that may occur due to delay in treatment are prevented.

Acknowledgements We would like to thank all the patients who participated in the study. 
Author Contribution Study design: Y.S.

Study conduct and data collection: Y.S, N.Ö, B.E.A

Data analysis: Y.S.

Writing paper: Y.S.

Revising paper: Y.S, N.Ö, B.E.A

\section{Declarations}

Ethical Considerations The approval from Erciyes University's non-interventional clinical research ethics committee (2020/515) was obtained. Informed consent was obtained from the patients. In addition, study permission on COVID-19 was obtained from the Ministry of Health.

Conflict of Interest The authors declare no competing interests.

\section{References}

Açıksarı, K., \& Kınık, K. (2020). Process management and outcomes of the emergency department of a training and research hospital in Turkey during the coronavirus disease 2019 pandemic. Anatolian Clinic Journal of Medical Sciences, 25, 263-283. https://doi.org/10.21673/anadoluklin.740776.

Ahorsu, D. K., Lin, C. Y., Imani, V., Saffari, M., Griffiths, M. D., \& Pakpour, A. H. (2020). The fear of COVID19 scale: Development and initial validation. International Journal of Mental Health and Addiction, 1-9. https://doi.org/10.1007/s11469-020-00270-8.

Albert, K. M., \& Newhouse, P. A. (2019). Estrogen, stress, and depression: Cognitive and biological interactions. Annual Review of Clinical Psychology, 15, 399-423. https://doi.org/10.1146/annurev-clinpsy-050718-095557.

Bakioğlu, F., Korkmaz, O., \& Ercan, H. (2020). Fear of COVID-19 and positivity: Mediating role of intolerance of uncertainty, depression, anxiety, and stress. International Journal of Mental Health and Addiction, 1-14. https://doi.org/10.1007/s11469-020-00331-y.

Boserup, B., McKenney, M., \& Elkbuli, A. (2020). The impact of the COVID-19 pandemic on emergency department visits and patient safety in the United States. The American Journal of Emergency Medicine, 38(9), 1732-1736. https://doi.org/10.1016/j.ajem.2020.06.007.

Casanova, M., Pagani Bagliacca, E., Silva, M., Patriarca, C., Veneroni, L., Clerici, C. A., Spreafico, F., Luksch, R., Terenziani, M., Meazza, C., Podda, M., Biassoni, V., Schiavello, E., Chiaravalli, S., Puma, N., Bergamaschi, L., Gattuso, G., Sironi, G., Massimino, M., \& Ferrari, A. (2020). How young patients with cancer perceive the COVID-19 (coronavirus) epidemic in Milan, Italy: Is there room for other fears? Pediatric Blood \& Cancer, 67(7), e28318. https://doi.org/10.1002/pbc.28318.

Castro, V. M., \& Perlis, R. H. (2020). Electronic health record documentation of psychiatric assessments in Massachusetts emergency department and outpatient settings during the coronavirus disease 2019 (COVID19) pandemic. JAMA Network Open, 3(6), e2011346-e2011346. https://doi.org/10.1101/2020.03.30. 20048207.

Catania, C., Spitaleri, G., Del Signore, E., Attili, I., Radice, D., Stati, V., et al. (2020). Fears and perception of the impact of COVID-19 on patients with lung cancer: A mono-institutional survey. Frontiers in Oncology, 10, 2237. https://doi.org/10.3389/fonc.2020.584612.

Comelli, I., Scioscioli, F., \& Cervellin, G. (2020). Impact of the COVID-19 epidemic on census, organization and activity of a large urban Emergency Department. Acta Bio Medica: Atenei Parmensis, 91(2), 45. https://oi. org/10.23750/abm.v91i2.9565.

Correia, M., Constâncio, V., Silva, J. C., Lima, P., Moreira, M., Antunes, L. F., \& Fonseca, M. (2020). Is there an impact of covid-19 on admission of patients to the emergency department for vascular surgery? Annals of Vascular Surgery, 69, 100-104. https://doi.org/10.1016/j.avsg.2020.08.002.

Cummings, M. J., Baldwin, M. R., Abrams, D., Jacobson, S. D., Meyer, B. J., Balough, E. M., et al. (2020). Epidemiology, clinical course, and outcomes of critically ill adults with COVID-19 in New York City: A prospective cohort study. Lancet., 395, 1763-1770. https://doi.org/10.1016/S0140-6736(20)31189-2.

Fitzpatrick, K. M., Harris, C., \& Drawve, G. (2020). Fear of COVID-19 and the mental health consequences in America. Psychological Trauma Theory Research Practice and Policy, 12, 17-21. https://doi.org/10.1037/ tra0000924.

Garrafa, E., Levaggi, R., Miniaci, R., \& Paolillo, C. (2020). When fear backfires: Emergency department accesses during the Covid-19 pandemic. Health Policy, 124(12), 1333-1339. https://doi.org/10.1016/j. healthpol.2020.10.006. 
Kaufman, H. W., Chen, Z., Niles, J., \& Fesko, Y. (2020). Changes in the number of US patients with newly identified cancer before and during the coronavirus disease 2019 (COVID-19) pandemic. JAMA Network Open, 3(8), e2017267. https://doi.org/10.1001/jamanetworkopen.2020.17267.

Koksal, E., Dost, B., Terzi, Ö., Ustun, Y. B., Özdin, S., \& Bilgin, S. (2020). Evaluation of depression and anxiety levels and related factors among operating theater workers during the novel coronavirus (COVID-19) pandemic. Journal of PeriAnesthesia Nursing., 35(5), 472-477. https://doi.org/10.1016/j.jopan.2020.06.017.

Labrague, L. J., \& de Los Santos, J. A. A. (2020). Fear of Covid-19, psychological distress, work satisfaction and turnover intention among frontline nurses. Journal of Nursing Management, 29, 1-9. https://doi.org/10. 1111/jonm.13168.

Li, S. H., \& Graham, B. M. (2017). Why are women so vulnerable to anxiety, trauma-related and stress-related disorders? The potential role of sex hormones. The Lancet Psychiatry, 4(1), 73-82. https://doi.org/10.1016/ S2215-0366(16)30358-3.

Mahil, S. K., Dand, N., Mason, K. J., Yiu, Z. Z., Tsakok, T., Meynell, F., et al. (2021). Factors associated with adverse COVID-19 outcomes in patients with psoriasis-insights from a global registry-based study. The Journal of Allergy and Clinical Immunology, 147(1), 60-71. https://doi.org/10.1016/j.jaci.2020.10.007.

Ornell, F., Schuch, J. B., Sordi, A. O., \& Kessler, F. H. P. (2020). Pandemic fear and COVID-19: Mental health burden and strategies. Brazilian Journal of Psychiatry, 42(3), 232-235. https://doi.org/10.1590/1516-44462020-0008.

Perz, C. A., Lang, B. A., \& Harrington, R. (2020). Validation of the fear of COVID-19 scale in a US college sample. International Journal of Mental Health and Addiction, 1-11. https://doi.org/10.1007/s11469-020-00356-3.

Pope, J. E. (2020). What does the COVID-19 pandemic mean for rheumatology patients? Current Treatment Options in Rheumatology., 6, 71-74. https://doi.org/10.1007/s40674-020-00145-y.

Romantini, F., Saldutto, P., Maselli, G., Ferritto, M., Ranieri, M., Castellani, D., \& Vicentini, C. (2020). Patient's fear of being infected, another complication of COVID-19 outbreak: A lesson learned from a case of lifethreatening urolithiasis. Journal of Endourology Case Reports., 6(4), 402-404. https://doi.org/10.1089/cren. 2020.0120 .

Rubinow, D. R., \& Schmidt, P. J. (2019). Sex differences and the neurobiology of affective disorders. Neuropsychopharmacology, 44(1), 111-128. https://doi.org/10.1038/s41386-018-0148-z.

Saghafian, S., Austin, G., \& Traub, S. J. (2015). Operations research/management contributions to emergency department patient flow optimization: Review and research prospects. IIE Transactions on Healthcare Systems Engineering, 5(2), 101-123. https://doi.org/10.1080/19488300.2015.1017676.

Sigorski, D., Sobczuk, P., Osmola, M., Kuć, K., Walerzak, A., Wilk, M., Ciszewski, T., Kopeć, S., Hryń, K., Rutkowski, P., Stec, R., Szczylik, C., \& Bodnar, L. (2020). Impact of COVID-19 on anxiety levels among patients with cancer actively treated with systemic therapy. ESMO open., 5(5), e000970. https://doi.org/10. 1136/esmoopen-2020-000970.

Soni, M., Curran, V. H., \& Kamboj, S. K. (2013). Identification of a narrow post-ovulatory window of vulnerability to distressing involuntary memories in healthy women. Neurobiology of Learning and Memory, 104, 32-38. https://doi.org/10.1016/j.nlm.2013.04.003.

Vanni, G., Materazzo, M., Pellicciaro, M., Ingallinella, S., Rho, M., Santori, F., et al. (2020). Breast cancer and COVID-19: The effect of fear on patients' decision-making process. In Vivo, 34, 1651-1659. https://doi.org/ 10.21873/invivo.11957.

Wang, C., Pan, R., Wan, X., Tan, Y., Xu, L., Ho, C. S., \& Ho, R. C. (2020). Immediate psychological responses and associated factors during the initial stage of the 2019 coronavirus disease (COVID-19) epidemic among the general population in China. International Journal of Environmental Research and Public Health, 17(5), 1729. https://doi.org/10.3390/ijerph17051729.

WHO (2020). Director-General's opening remarks at the media briefing on COVID-19 - 11 March 2020. https:// www.who.int/dg/speeches/detail/who-director-general-sopening-remarks-at-the-media-briefing-on-covid19\%2D\%2D-11-march-2020. Accessed: 06.04.2020.

WongLaura, E., HawkinsJessica, E., \& MurrellKaren, L. (2020). Where are all the patients? Addressing Covid19 fear to encourage sick patients to seek emergency care. NEJM Catalyst Innovations in Care Delivery. https://doi.org/10.1056/CAT.20.0193.

Wu, Z., \& McGoogan, J. M. (2020). Characteristics of and important lessons from the coronavirus disease 2019 (COVID-19) outbreak in China: Summary of a report of 72314 cases from the Chinese Center for Disease Control and Prevention. JAMA, 323(13), 1239-1242. https://doi.org/10.1001/jama.2020.2648.

Publisher's Note Springer Nature remains neutral with regard to jurisdictional claims in published maps and institutional affiliations. 